\title{
Termorregulação e desempenho de tourinhos Sindi e Guzerá, no agreste paraibano ${ }^{1}$
}

\author{
Dermeval A. Furtado ${ }^{2}$, Adriana P. Peixoto ${ }^{3}$, Jonh E. F. Regis ${ }^{4}$, \\ José W. B. do Nascimento ${ }^{2}$, Tiago G. P. Araujo ${ }^{5}$ \& Ana C. C. Lisboa ${ }^{6}$
}

\begin{abstract}
RESUMO
Neste trabalho objetivou-se avaliar os índices bioclimáticos que influenciam as varáveis fisiológicas, desempenho e consumo de nutrientes de tourinhos das raças Gir e Guzerá. O estudo foi realizado na Estação Experimental de Alagoinha/EMEPA-PB, no município de Alagoinha, no agreste paraibano, Brasil, utilizando-se 16 tourinhos das raças Sindi e Guzerá (8 animais de cada raça), com média de 31,5 $\pm 1,5$ meses de idade, mantidos confinados. O delineamento estatístico utilizado foi o de blocos inteiramente casualizados, com 8 repetições, em parcelas subdivididas, com raça na parcela principal e horários $(6$, 12 e 16 h) na subparcela. A temperatura retal, frequência respiratória e temperatura superficial dos animais se mantiveram dentro da faixa considerada normal para a espécie bovina. Não houve influência negativa no consumo de nutrientes e os animais tiveram um desempenho em ganho de peso acima do esperado, demonstrando que estão adaptados às condições de Nordeste brasileiro, já que não houve alterações em seus parâmetros fisiológicos, considerados dentro da faixa normal e ainda apresentaram excelente desempenho produtivo e de consumo de nutrientes.
\end{abstract}

Palavras-chave: adaptabilidade, ambiência, desempenho produtivo

\section{Thermoregulation and performance of Sind and Guzera young bulls in 'Agreste' region of Paraiba State}

\begin{abstract}
The objective of this study was to evaluate the bioclimatic indices that influence physiological variables, performance and nutrient intake by Gir and Guzera young bulls. The work was conducted at the Experimental Station of Alagoinha/EMEPA-PB in Alagoinha town in 'Agreste' region of Paraiba state, Brazil, using 16 young bulls of Sind and Guzera breeds (8 animals of each breed), with a mean $31.5 \pm 1.5$ months of age, kept under confined conditions. The statistical design used was randomized blocks with eight replications in split plot with breed in the main plot and time $(6,12$ and $16 \mathrm{~h})$ as subplots. Rectal temperature, respiratory rate and surface temperature of the animals remained within the normal range for the bovine species. There was no negative influence on food intake and the animals had weight gain higher than expected, demonstrating that they are adapted to the conditions of northeastern Brazil, since there were no changes in their physiological parameters considered within the normal range and still showed excellent growth performance and nutrient intake.
\end{abstract}

Key words: adaptability, ambience, productive performance

Parte da Dissertação de Mestrado da segunda autora, apresentada à COPEAG/UAEA/UFCG. Financiada pela CAPES/CNPq

UFCG. CEP 58109-180, Campina Grande, PB. Fone: (83) 2101-1486. E-mail: dermeval@deag.ufcg.edu.br; wallace@deag.ufcg.edu.br

EMATER/PB. Alagoinha, PB. CEP 58390-000. E-mail: adrizoo@hotmail.com

EMEPA/PB. Alagoinha, PB. CEP 58390-000. E-mail: regis83@gmail.com

Doutorando em Engenharia Agrícola da UFCG. CEP 58429-140. Campina Grande, PB. Fone: (83) 9622-5710. E-mail: tiagoaraujo@yahoo.com

${ }^{6}$ UATEC/UFCG, Campus de Sumé, PB. CEP 58540-000. Sumé, PB. Fone: (83) 3353-1850. E-mail: aclisboa@ufcg.edu.br 


\section{INTRODUÇÃO}

Para o Brasil, principalmente na região nordeste, o estresse térmico é um agravante à produção animal, onde são registradas altas temperaturas, consequência da elevada radiação solar, com alta amplitude anual na temperatura do ar (Souza et al., 2007; Azevedo et al., 2008; Façanha et al., 2010) e, na maioria dessa região, existem duas estações bem distintas, uma chamada estação seca, onde se registram altas temperaturas associadas à baixa umidade relativa do ar, e outra chuvosa, caracterizada por apresentar temperaturas mais amenas e uma umidade relativa do ar mais elevada.

Dentro da produção animal se destaca, no Nordeste brasileiro, a criação de bovinos, uma das principais fontes de renda da agropecuária, principalmente de zebuínos e, neste contexto, se destacam os animais das raças Sindi e Guzerá, por apresentarem dupla aptidão e alta eficiência produtiva e reprodutiva, grande rusticidade e serem bastante tolerantes ao estresse térmico (Turco et al., 2006; Souza et al., 2007; Furtado et al., 2012), comum em climas tropicais, possuem facilidade a longas caminhadas e resistentes a ectoparasitos.

Os bovinos, tal como outros ruminantes, são animais homeotérmicos, tendendo a manter a temperatura corporal constante através do fluxo de calor determinado por processos que dependem da temperatura e da umidade relativa do ar (Azevedo et al., 2008). As adversidades climáticas podem provocar alterações nos processos fisiológicos, como temperatura corporal e retal, frequência respiratória e cardíaca (Souza et al., 2007; Furtado et al., 2012) que podem ser mecanismos de avaliação direta da alteração do equilíbrio térmico do animal.

A zona de conforto térmico para bovinos depende de vários fatores, como raça, idade, sexo e do grau de tolerância ao calor, que pode estar ligado às características corporais e aos fatores genéticos (Bianchini et al., 2006). Segundo Ferreira (2005) podese considerar, como zona de conforto térmico (ZCT) para zebuínos, temperaturas na faixa de 10 a $27^{\circ} \mathrm{C}$, sendo o limite crítico superior de $35^{\circ} \mathrm{C}$ (Baeta \& Souza, 2010), com umidade relativa do ar entre 50 e $70 \%$. Vários índices têm sido utilizados para caracterizar o ambiente térmico entre os quais se destacam o índice de temperatura e umidade (ITU) e o índice de temperatura de globo negro e umidade (ITGU), utilizados para avaliar o conforto térmico ambiente; atualmente, existem limites de ITU e ITGU definidos para diversas espécies de animais, em especial dos bovinos, como os da National Weather Service USA em que, segundo citações de Souza et al. (2002), valores até 74 define situação de conforto; de 74 a 78 , situação de alerta; de 79 a 84, situação perigosa e acima de 84, emergência.

A temperatura do corpo é uma boa medida para indicar a tolerância animal às condições adversas do clima, além do número de movimentos respiratórios, sendo que aumentos na temperatura do ar sempre acarretam aumentos da temperatura retal e frequência respiratória de bovinos. Se a temperatura do ar está muito elevada, há um aumento no esforço animal para perder calor, para que não haja aumento na temperatura do corpo e em algumas situações, os mecanismos de termorregulação podem não ser suficientes para evitar a elevação da temperatura retal, superficial e da frequência respiratória (Furtado et al., 2012).

De acordo com Ferreira (2005) e Baêta \& Souza (2010) os limites considerados normais para temperatura retal para bovinos são de 38 a $39,5^{\circ} \mathrm{C}$, com frequência respiratória entre 15 e $30 \mathrm{mov} \mathrm{min}^{-1}$. A temperatura de pele depende, sobremaneira, das condições do ambiente, umidade, temperatura do ar, vento e das condições fisiológicas, como vascularização e evaporação pelo suor.

O desempenho animal é determinado pelo consumo de nutrientes, sua digestibilidade e metabolismo e entre os fatores que determinam a qualidade dos alimentos, sendo o consumo de nutrientes o fator de maior importância, com influência direta sobre o desempenho animal (Detmann et al., 2008). O consumo de matéria seca pode produzir mais impacto na produção animal do que as variações na composição química ou disponibilidade dos nutrientes e, entre os fatores que influenciam este consumo em ruminantes, se destacam a genética e a adaptabilidade do animal, o alimento, sanidade, manejo e os fatores bioclimáticos.

Objetivou-se com este trabalho avaliar os índices bioclimáticos que influenciam as variáveis fisiológicas, desempenho e consumo de nutrientes de bovinos jovens (tourinhos) das raças Gir e Guzerá e as condições climáticas do agreste paraibano.

\section{Material e MÉTOdos}

A pesquisa foi realizada na Estação Experimental de Alagoinha, pertecente à Empresa Estadual de Pesquisa Agropecuária da Paraíba S.A. - EMEPA, localizada na mesorregião do agreste paraibano, no município de Alagoinha, PB. A estação fica situada nas coordenadas geográficas $6^{\circ} 57^{\prime}$ 00' S e 35 32' 42"'W. Gr., com altitude de 154 m. O clima da área, segundo a classificação de Köppen, é do tipo As' (quente e úmido), a época chuvosa tem início no mês de fevereiro ou março, prolongando-se até julho ou agosto. As precipitações pluviais atingem uma média de $990 \mathrm{~mm}$ anuais.

O experimento foi realizado no período de julho a setembro, perfazendo 73 dias de testes, compreendendo13 dias de período pré-experimental e 60 de coleta de dados. Foram utilizados 16 bovinos jovens das raças Sindi e Guzerá (8 animais de cada raça), com idade média de $30 \pm 5$ e $33 \pm 3$ meses, respectivamente. Os animais foram vermifugados e alojados em instalação com orientação no sentido Norte-Sul, com as seguintes dimensões: 11,5 m de comprimento e 13,5 m de largura, pé direito de 3,25 m, piso cimentado e comedouros individuais de alvenaria separados por cerca de madeira. Durante o período de estabulação os animais foram mantidos presos por meio de corda. Os animais passaram por um regime de confinamento diário de $12 \mathrm{~h}$, das $5 \mathrm{~h}$ às $17 \mathrm{~h}$ e soltos às $17 \mathrm{~h}$ e passavam a noite em piquetes.

As variáveis ambientais no ambiente interno das instalações foram coletadas com a utilização de dataloggers (HOBO®H8), instalado em quatro pontos do galpão e os dados coletados foram: temperatura do ar (TA), temperatura de bulbo úmido (Tbu) e temperatura do globo negro (Tgn), a cada 2 h. A temperatura do globo negro (Tgn) foi obtida com a implantação do sensor na altura de massa dos animais. A velocidade do 
Tabela 1. Composição química dos ingredientes da dieta experimental com base na matéria seca

\begin{tabular}{|c|c|c|c|c|c|c|c|c|}
\hline Ingredientes & MS & MM & PB & FDN & FDA & $\mathrm{EE}$ & CNF & $\overline{\text { DIVMS }}$ \\
\hline Capim elefante & 26,51 & 8,33 & 6,21 & 63,33 & 23,54 & 1,23 & 20,90 & 47,25 \\
\hline Farelo de milho & 84,51 & 3,63 & 11,35 & 56,47 & 5,96 & 11,49 & 17,06 & 79,31 \\
\hline Farelo de trigo & 91,33 & 5,02 & 18,00 & 58,32 & 23,01 & 4,90 & 13,75 & 63,24 \\
\hline Farelo de soja & 84,79 & 6,58 & 46,93 & 39,83 & 9,24 & 2,13 & 4,53 & 90,01 \\
\hline Suplemento mineral & 96,01 & 85,33 & - & - & - & - & - & - \\
\hline
\end{tabular}

MS - matéria seca; MM - matéria mineral; PB - proteína bruta; FDN - fibra em detergente neutro; FDA - fibra em detergente ácido; EE - extrato etéreo; CNF - carboidratos não fibrosos; DIVMS - digestibilidade in vitro da matéria seca

vento (VV) e a umidade relativa do ar (UR) foram mensuradas com a utilização de um anemômetro digital portátil, realizadas em quatro pontos das instalações, próximo aos sensores, tendo-se feito uma média desses dados.

Através dos dados coletados foram calculados os índices de temperatura e umidade (ITU), índice de temperatura do globo negro e umidade (ITGU), através das equações citadas por Souza et al. (2002).

Os índices fisiológicos analisados foram: temperatura retal (TR), frequência respiratória (FR) e temperatura da pele (TP). As variáveis fisiológicas foram medidas duas vezes por semana, em três horários distintos, às 6,12 e $16 \mathrm{~h}$. A medição da TR foi coletada através da introdução de um termômetro clínico veterinário, com escala até $44^{\circ} \mathrm{C}$, diretamente no reto do animal, a uma profundidade de $5 \mathrm{~cm}$, durante $2 \mathrm{~min}$. A FR foi realizada através da observação direta no flanco do animal, contandose o número de movimentos durante $15 \mathrm{~s}$ e o valor obtido multiplicado por 4, obtendo-se a frequência respiratória por minuto. Para obtenção da TP utilizou-se um termômetro infravermelho digital, na região da cabeça, dorso, perna e ventre dos animais, a uma distância aproximada de $50 \mathrm{~cm}$, realizandose suas médias para obtenção do valor final.

A dieta completa foi formulada com base no NRC (1996), visando atender às exigências nutricionais dos bovinos jovens das raças Sindi e Guzerá em terminação com peso vivo médio de $317 \pm 38 \mathrm{~kg}$ e $404 \pm 33 \mathrm{~kg}$, com ganho de peso, consumo de matéria seca e proteína bruta de $0,500 \mathrm{~kg} \mathrm{~d}^{-1} ; 8,2 \mathrm{~kg} \mathrm{~d}^{-1} \mathrm{e} 10,67 \%$, respectivamente. A composição química dos ingredientes está apresentada na Tabela $1 \mathrm{e}$ as composições percentuais e químicas da dieta experimental se encontram na Tabela 2.

Tabela 2. Participação dos ingredientes e composição química da dieta experimental com base na matéria seca

\begin{tabular}{lr}
\hline \multicolumn{1}{c}{ Ingredientes } & (kg MS) \\
Capim elefante & 65,00 \\
Farelo de milho & 21,80 \\
Farelo de trigo & 8,65 \\
Farelo de soja & 3,50 \\
Uréia & 0,80 \\
Suplemento mineral & 0,24 \\
\hline \multicolumn{1}{c}{ Composição química } & $\mathbf{( \% )}$ \\
Matéria seca & 46,26 \\
Matéria mineral & 6,71 \\
Proteína bruta & 12,12 \\
Extrato etéreo & 3,46 \\
Carboidratos não fibrosos & 33,00 \\
Fibra em detergente neutro & 59,54 \\
Fibra em detergente ácido & 18,34 \\
Digestibilidade in vitro da matéria seca & 56,37 \\
\hline
\end{tabular}

O fornecimento da ração foi realizado individualmente, duas vezes ao dia, às $6 \mathrm{~h}$ e às $13 \mathrm{~h}$; a quantidade de ração fornecida por cada animal foi de 20,87 $\mathrm{kg}$ de volumoso e $2,0 \mathrm{~kg}$ de concentrado, homogeneizada e fornecida aos animais; diariamente, era ajustada de acordo com o consumo do dia anterior, permitindo sobras em torno de $20 \%$ do total fornecido.

Para a estimativa dos consumos de matéria seca (MS), matéria mineral (MM), proteína bruta (PB), extrato etéreo (EE), carboidratos não fibrosos (CNF), fibra em detergente neutro (FDN), fibra em detergente ácido (FDA) e digestibilidade in vitro da matéria seca (DIVMS), a quantidade de ração foi pesada e registrada diariamente, assim como as sobras de cada animal, para se ter o consumo diário individual. As sobras foram coletadas diariamente e feita uma única composta; em seguida, foi feita a secagem em estufa a $55{ }^{\circ} \mathrm{C}$ por $72 \mathrm{~h}$, sendo posteriormente moídas em moinho de facas tipo Wiley, para determinação dos teores de matéria seca e dos nutrientes. As análises foram realizadas no Laboratório de Nutrição Animal e Avaliação de Alimentos do CCA/UFPB. As análises química e bromatológicas foram realizadas de acordo com as metodologias descritas por Silva \& Queiroz (2002). Calculouse a composição da dieta efetivamente consumida pelos animais, a partir do consumo voluntário de cada nutriente da dieta dividido pela MS consumida e multiplicado por 100 .

Os parâmetros produtivos analisados foram o ganho de peso total (GPT), ganho de peso diário (GPD) e o consumo de matéria seca (CMS). O GPT foi calculado pela diferença entre o peso final e o peso inicial dos animais e o GPD dividindo-se o GPT pelo número de dias do experimento. O consumo de matéria seca foi a relação entre o consumo de matéria seca e o ganho de peso correspondente. Os animais foram pesados a cada 14 dias, durante o período experimental, após $12 \mathrm{~h}$ do último arraçoamento, para controle de ganho de peso (GP) e ganho de peso médio diário (GPMD).

Visando à análise estatística das respostas fisiológicas (TR, FR e TP), o delineamento estatístico utilizado foi o de blocos inteiramente casualizados com 8 repetições em parcelas subdivididas, com raça na parcela principal e horários $(6,12$ e $16 \mathrm{~h}$ ) na subparcela. Os dados foram avaliados por meio de análise de variância e as médias comparadas pelo teste Tukey, a 5\% de probabilidade pelo programa estatístico Assistat 7.5, desenvolvido por Silva \& Azevedo (2006).

\section{RESULTADOS E DISCUSSÃO}

Os valores médios dos índices bioclimáticos se encontram na Tabela 3, na qual se observa que a temperatura média do ar 
foi, pela manhã, de $24,26^{\circ} \mathrm{C}$ e à tarde, $26,82^{\circ} \mathrm{C}$; portanto, com esta temperatura dentro da zona de conforto térmico (ZCT) para bovinos (Ferreira, 2005; Baeta \& Souza, 2010), que estabelecem uma faixa de 16 a $28^{\circ} \mathrm{C}$ para bovinos indianos. A criação de animais dentro da ZCT é imprescindível na produção animal, já que eles têm gasto mínimo de energia para mantença, maximizando o crescimento e, em consequência, a produção.

Tabela 3. Valores médios dos índices bioclimaticos temperatura do ar (TA), umidade relativa do ar (UR), velocidade do vento (VV), índice de temperatura e umidade (ITU) e índices de temperatura de globo e umidade (ITGU)

\begin{tabular}{|c|c|c|c|c|c|}
\hline \multirow{3}{*}{ Índice } & \multicolumn{5}{|c|}{ Período do dia } \\
\hline & \multicolumn{2}{|r|}{ Manhã } & \multicolumn{2}{|r|}{ Tarde } & \multirow{2}{*}{ Média geral } \\
\hline & Média & Amplitude & Média & Amplitude & \\
\hline TA $\left({ }^{\circ} \mathrm{C}\right)$ & 24,26 & $24,13-24,39$ & 26,82 & $26,65-26,99$ & 25,54 \\
\hline UR (\%) & 80,28 & $79,61-80,95$ & 71,58 & $69,11-74,04$ & 75,93 \\
\hline ITU & 72,81 & $72,62-73,00$ & 75,75 & $75,47-76,03$ & 74,28 \\
\hline ITGU & 73,54 & $73,26-73,81$ & 76,52 & $76,15-76,88$ & 75,03 \\
\hline $\mathrm{V}\left(\mathrm{m} \mathrm{s}^{-1}\right)$ & 4,31 & $3,29-5,33$ & 5,35 & $4,34-6,36$ & 4,83 \\
\hline
\end{tabular}

A umidade relativa média durante o período da manhã foi de $80,28 \%$ e, no período da tarde foi de $71,58 \%$, caracterizando um estresse ameno (72 a 79\%), segundo estudos de Pereira (2005). Esta menor umidade relativa no período da tarde está associada com a elevação da temperatura do ar e da carga térmica radiante, que também foram relatadas por Souza et al. (2007); Façanha et al. (2010) e Oliveira et al. (2012), que analisaram índices de tolerância ao calor com bovinos na região semiárida.

Tomando por base as citações de Souza et al. (2002), o ITU e o ITGU médio indicam que os animais estavam em situação de alerta, caracterizando um estresse térmico para os animais. Turco et al. (2006) realizando o zoneamento bioclimático para bovinos leiteiros no estado da Bahia, citam que, mesmo nos meses mais frios do ano, apresentaram situação de alerta, semelhante à da presente pesquisa o que, no período mais quente do ano, pode caracterizar situação de perigo. Azevedo et al. (2008) também relatam, avaliando a adaptabilidade de bovinos e as condições do estado do Piauí, que no período chuvoso o ambiente foi considerado estressante.

As médias da velocidade do vento foram de 4,31 e 5,35 $\mathrm{m} \mathrm{s}^{-}$ 1, para os períodos da manhã e tarde, respectivamente, ventilação que contribuiu para amenizar a temperatura do ar o ITU e ITGU, tornando o ambiente mais ameno, contribuindo bastante para a eliminação de gases e odores (Baeta \& Souza, 2010) presentes na instalação. Valores inferiores aos desta pesquisa foram relatados por Façanha et al. (2010), estudando a temperatura superficial de vacas no semiárido baiano, com média de $2,6 \mathrm{~m} \mathrm{~s}^{-1}$ e bastante variação ao longo do ano, destacando que esta ventilação é benéfica uma vez que contribui para a termólise convectiva, amenizando a sensação de calor imposta pelas altas temperaturas.

As médias de temperatura retal $\left({ }^{\circ} \mathrm{C}\right)$ dos bovinos em função dos horários se encontram na Tabela 4 . Não houve interação entre as raças e horários observando-se efeito significativo (P $<0,01)$ apenas entre os horários. Os valores da TR foram, à tarde, superiores aos do meio-dia e da manhã, sendo que o do meio dia foi superior ao da manhã. Apesar do aumento na temperatura retal observado nas duas raças da manhã para a tarde, em todos os horários os animais mantiveram TR dentro dos valores normais, mostrando que à tarde, quando o ambiente foi classificado como de alerta, com médias de 75,7 e 76,5, para ITU e ITGU, respectivamente, os animais não alteraram a TR, sinalizando sua adaptação na região nordestina, com boa resposta fisiológica para as condições térmicas da região.

Tabela 4. Médias para temperatura retal, frequência respiratória e temperatura superficial dos bezerros Sindi e Guzerá, nos diferentes horários, com desvio padrão (D.P)

\begin{tabular}{|c|c|c|c|c|c|}
\hline \multirow{2}{*}{ Raças } & \multicolumn{3}{|c|}{ Horários } & \multirow{2}{*}{ Média } & \multirow{2}{*}{ D.P } \\
\hline & 6:00 & $12: 00$ & 16:00 & & \\
\hline \multicolumn{6}{|c|}{ Temperatura retal $\left({ }^{\circ} \mathrm{C}\right)$} \\
\hline Sindi & $38,67 \mathrm{c}$ & $38,81 \mathrm{~b}$ & $39,19 \mathrm{a}$ & 38,89 & 0,19 \\
\hline Guzerá & $38,72 \mathrm{c}$ & $38,81 \mathrm{~b}$ & $39,11 \mathrm{a}$ & 38,88 & 0,15 \\
\hline Média & 38,69 & 38,81 & 39,15 & 38,88 & 0,17 \\
\hline \multicolumn{6}{|c|}{ Frequência respiratória (mov $\min ^{-1}$ ) } \\
\hline Sindi & 23,25 & 23,64 & 23,82 & 23,57 & 3,31 \\
\hline Guzerá & 23,53 & 23,71 & 23,71 & 23,65 & 3,12 \\
\hline Média & 23,39 & 23,67 & 23,76 & 23,60 & 1,56 \\
\hline \multicolumn{6}{|c|}{ Temperatura de pele $\left({ }^{\circ} \mathrm{C}\right)$} \\
\hline Sindi & $28,16 \mathrm{c}$ & $32,15 \mathrm{a}$ & $31,93 \mathrm{~b}$ & 30,74 & 0,69 \\
\hline Guzerá & $28,03 \mathrm{c}$ & $32,06 \mathrm{a}$ & $31,67 \mathrm{~b}$ & 30,58 & 0,59 \\
\hline Média & 28,09 & 32,10 & 31,80 & 30,66 & 0,43 \\
\hline
\end{tabular}

Médias na linha, seguidas por letras minúsculas diferentes, diferem pelo teste de Tukey $(p<0,01)$ CV $(\%)=0,19$

Respostas semelhantes a esta foram relatadas por Oliveira et al. (2012), em trabalhos com bovinos Sindi, ao citarem uma temperatura retal mais elevada à tarde, em razão do acúmulo do calor no organismo animal, resultante do calor recebido e produzido internamente, além da incapacidade de eliminar este excesso de energia.

Souza et al. (2007) relatam que, à tarde, fêmeas da raça Sindi criadas no semiárido paraibano, com idade média de 18 meses, criadas sob condições de estresse térmico, apresentaram maior TR à tarde, advinda principalmente do aumento da carga térmica adicional recebida da radiação solar, resultando em um aumento da quantidade de calor interno. Ferreira et al. (2006) citam, em trabalhos com animais mestiços (1/2 Gir e 1/2 Holandês) que, mesmo em ambiente controlado, a TR foi mais elevada à tarde que a da manhã, e que referido fato esta associado ao armazenamento de calor pelo aumento da temperatura corporal da manhã para a tarde, provocando hipertermia nos animais. Furtado et al. (2012) também observaram, em trabalhos na mesma região da presente pesquisa, com bezerros Sindi e Guzerá, uma temperatura retal mais elevada no período da tarde mas se mantiveram dentro da normalidade.

Existe uma ampla discussão sobre os limites de conforto térmico para animais zebuínos jovens, principalmente nos criados em zonas áridas e semiáridas. Bianchini et al. (2006) citam, em pesquisa com diferentes grupos genéticos de bovinos naturalizados brasileiros e exóticos, que animais de raças puras de origem indiana, como também animais naturalizados, apresentaram características mais condizentes com a tolerância ao calor. Azevedo et al. (2008) constataram, avaliando bovinos da raça Pé-Duro criados sob estresse térmico,que os mesmos 
mantiveram a TR dentro da normalidade para a espécie bovina, independente do período do ano, sexo, idade e horário, indicando a adaptação da raça ao ambiente, e sugerem mais pesquisas para determinação dos valores críticos para esses índices, em especial para animais adaptados ao clima tropical.

Observa-se que, nas médias da frequência respiratória (Tabela 4) não houve diferença significativa $(\mathrm{p}>0,05)$ entre os horários e as raças. As médias de FR observadas indicaram que a frequência respiratória permaneceu dentro da faixa de normalidade, que varia entre 15 e $30 \mathrm{mov} \mathrm{min}^{-1}$. Para Hahn et al. (1997) ha frequência de ate $60 \mathrm{mov} \mathrm{min}^{-1}$ indicando a adaptação desses animais a tais condições climáticas.

Segundo Ferreira et al. (2006) nessas condições, os animais podem aumentar a sudorese na tentativa de evitar a hipertermia e a menor utilização da FR para perder calor é uma estratégia energética que torna a vida nos trópicos menos dispendiosa e mais confortável. Turco et al. (1990) notaram, em trabalhos na região semiárida brasileira com animais da raça Sindi que, mesmo sob estresse térmico, os animais conseguiram manter a TR e a FR dentro da normalidade, demonstrando que, apesar da situação, os animais conseguiram manter a homeotermia e também tiveram boa ventilação, tanto no período da manhã como à tarde, fato que ajudou a manter a FR dentro da normalidade.

Analisando os valores médios para temperatura de pele (Tabela 4), observa-se que não houve interação entre os horários e raças, mas ocorreu diferença significativa $(\mathrm{p}<0,01)$ apenas entre os horários. Mesmo apresentando menor porte, a raça Sindi apresentou a temperatura da pele semelhante à Guzerá, diferente da situação apresentada por Façanha et al. (2010), ao citarem que, além dos fatores produtivos, em bovinos a maior parcela de temperatura corporal é devida ao calor liberado nos processos metabólicos que, complementados pela absorção de radiação, somatizam o total do estoque térmico do organismo animal, portando animais menores, tendem a ter uma temperatura superficial mais elevada.

Analisando os horários, A TS apresentou valor mais elevado ao meio-dia, seguido do horário das 16 h, demonstrando que, embora de forma indireta (os animais estavam confinados), a radiação solar afeta este parâmetro nos períodos de maior temperatura e menor umidade relativa do ar. Souza et al. (2007) relatam, em trabalhos com bovinos da raça Sindi e Furtado et al. (2012) em trabalhos com bezerros Sindi e Guzerá que, independente do período e da estação do ano (seca e chuvosa), a temperatura superficial foi mais elevada no período de maior temperatura.

Façanha et al. (2010) ressaltam, em trabalhos com vacas leiteiras mestiças com alta proporção de sangue holandês, em diferentes períodos do ano, valores médios de TS entre 34,53 e 36,50 (coleta em junho e dezembro) superiores, portanto, aos da presente pesquisa, o que demonstra a maior capacidade dos animais zebuínos em manter a TS mais baixa, melhorando o gradiente térmico entre a temperatura retal e a superficial, facilitando, em consequência, as trocas térmicas.

Turco et al. (1990) relatam, em trabalhos com bovinos Sindi, que esses animais apresentam características desejáveis para perda de calor, como pelos e pelames curtos. Segundo Martello et al. (2004), valores de 31,6 a 34,7 ${ }^{\circ} \mathrm{C}$ são considerados normais, ou seja, não se encontravam em condições de estresse pelo calor. A média geral da TP $30,66^{\circ} \mathrm{C}$ foi mais elevada que a média da temperatura do ar de $25,54^{\circ} \mathrm{C}$; desta forma, o animal transfere calor interno para o ambiente.

Observou-se efeito significativo $(\mathrm{p}<0,01)$ no ganho de peso total (GPT) e ganho de peso médio diário (GPMD) dos animais, com maior ganho de peso nos animais da raça Guzerá (Tabela 5). O ganho de peso médio diário foi de $0,63 \mathrm{~kg} \mathrm{~d}^{-1}$ para os bovinos jovens Sindi e de $0,82 \mathrm{~kg} \mathrm{~d}^{-1}$ para os da raça Guzerá enquanto as duas raças obtiveram ganho de peso acima do estimado, que foi de $0,500 \mathrm{~kg} \mathrm{~d}^{-1}$. A diferença significativa do GPMD pode ser justificada com base na Tabela 5, na qual se observa que o consumo de matéria seca em relação ao peso vivo foi maior para o Sindi; apesar disto, nota-se que o consumo de fibra pela mesma raça foi maior que o consumido pelos animais Guzerá. Embora a quantidade total de matéria seca de forragem produzida seja importante, deve-se ressaltar, como mais importante, sua qualidade, uma vez que é o aspecto da qualidade que influencia diretamente o desempenho animal.

Tabela 5. Peso inicial (PI), final (PF) e ganho de peso médio total (GPT) e ganho de peso médio diário (GPMD) dos bovinos jovens das raças Sindi e Guzerá

\begin{tabular}{lrrr}
\hline Variáveis & \multicolumn{1}{c}{ Sindi } & Guzerá & CV\% \\
GPT $(\mathrm{kg})$ & $46,12 \mathrm{~b}$ & $60,12 \mathrm{a}$ & 17,52 \\
$\mathrm{PI}(\mathrm{kg})$ & $317,00 \mathrm{~b}$ & $404,87 \mathrm{a}$ & 11,90 \\
PF $(\mathrm{kg})$ & $363,12 \mathrm{~b}$ & $465,00 \mathrm{a}$ & 10,66 \\
GPMD $\left(\mathrm{kg} \mathrm{d}^{-1}\right)$ & $0,63 \mathrm{~b}$ & $0,82 \mathrm{a}$ & 17,52 \\
\hline
\end{tabular}

Médias na linha seguidas das letras minúsculas diferentes diferem pelo teste de Tukey $(p<0,01)$

O ganho de peso pode ser afetado pelas condições climáticas adversas, ocasionando perdas na produção e produtividade individual de cada animal e, por consequência, de todo o rebanho. Esses fatos não ocorreram no presente experimento, em que os animais obtiveram ganho de peso acima do preconizado pelo NRC (1996), fato que demonstra a adaptabilidade dos bovinos zebuínos às condições do Nordeste brasileiro e, mais uma vez, a necessidade de se estabelecer índices de conforto térmico para animais zebuínos criados nos trópicos

O consumo de MS é uma variável complexa, passível de ser afetada por fatores relativos ao animal, ao alimento, à alimentação e às condições climáticas, que interagem e passam a ser determinantes (Costa et al., 2005). Mesmo possuindo menor porte, os animais da raça Sindi tiveram média do consumo de matéria seca em kg d ${ }^{-1}$ (Tabela 6), semelhante à dos animais da raça Guzerá, demonstrando a alta capacidade que a raça possui em consumir alimentos; deve-se, porém, observar que seu desempenho foi inferior ao da raça Guzerá que, apesar de ter consumido menos seu GPMD e GPT, foi bem superior ao ganho dos animais Sindi.

O consumo de matéria seca preconizado foi de $8,2 \mathrm{~kg} \mathrm{~d}^{-1}$ observando-se que os animais tiveram um consumo superior ao estimado (acima de 10,0 $\mathrm{kg} \mathrm{d}^{-1}$ ), o qual justifica o elevado ganho em desempenho que os animais obtiveram neste experimento. Referidos valores foram superiores aos encontrados por Pacheco et al. (2005), que estudaram o desempenho de novilhos super jovens, confinados e alimentados com cana-de-açúcar. 
Tabela 6. Médias e coeficientes de variação (CV) dos consumos de matéria seca (CMS), proteína bruta (CPB), fibra em detergente neutro (CFDN), fibra em detergente ácido (CFDA), matéria mineral (CMM) e extrato etéreo (CEE) dos bovinos jovens das raças Sindi e Guzerá

\begin{tabular}{lrrr}
\hline Variáveis & \multicolumn{1}{c}{ Sindi } & Guzerá & CV (\%) \\
CMS $\left(\mathrm{kg} \mathrm{d}^{-1}\right)$ & $10,01 \mathrm{a}$ & $10,24 \mathrm{a}$ & 10,09 \\
CMS $(\% \mathrm{PV})$ & $2,96 \mathrm{a}$ & $2,36 \mathrm{~b}$ & 7,00 \\
CMS $\left(\mathrm{g} \mathrm{kg}^{-0,75}\right)$ & $22,20 \mathrm{a}$ & $17,66 \mathrm{~b}$ & 6,98 \\
CPB $\left(\mathrm{kg} \mathrm{d}^{-1}\right)$ & $0,84 \mathrm{a}$ & $0,88 \mathrm{a}$ & 9,04 \\
CFDN $\left(\mathrm{kg} \mathrm{d}^{-1}\right)$ & $5,30 \mathrm{a}$ & $5,36 \mathrm{a}$ & 11,93 \\
CFDN $\left(\% \mathrm{PV}^{-1}\right)$ & $1,58 \mathrm{a}$ & $1,23 \mathrm{~b}$ & 7,10 \\
CFDN $\left(\mathrm{g} \mathrm{utm}^{-1}\right)$ & $11,86 \mathrm{a}$ & $9,24 \mathrm{~b}$ & 7,00 \\
CFDA $\left(\mathrm{kg} \mathrm{d}^{-1}\right)$ & $2,31 \mathrm{~b}$ & $2,66 \mathrm{a}$ & 12,35 \\
CMM $\left(\mathrm{kg} \mathrm{d}^{-1}\right)$ & $0,72 \mathrm{~b}$ & $0,83 \mathrm{a}$ & 6,39 \\
CEE $\left(\mathrm{kg} \mathrm{d}^{-1}\right)$ & $0,13 \mathrm{~b}$ & $0,16 \mathrm{a}$ & 10,75 \\
\hline
\end{tabular}

Médias seguidas de letras diferentes na mesma linha diferem entre si $(p<0,05)$ pelo teste de Tukey

Segundo Jorge et al. (2007) os animais Sindi são menores e mais leves que os da raça Guzerá, porém a raça possui circunferência torácica maior e esta variável permite que o animal possa aumentar seu consumo, embora não aumente seu desempenho. Esta afirmação justifica os dados apresentados neste trabalho, visto que o Sindi apresentou desempenho bem inferior ao do Guzerá, mas seu consumo em relação ao peso vivo foi superior.

Jorge et al. (2007) citam que rações com baixo teor de volumoso ou que a qualidade deste tubo com menos teor de fibra, seriam mais indicadas para as condições tropicais, em função de um incremento calórico menor. Rações compostas exclusivamente de volumoso se traduzem em maiores temperaturas corporais e maiores frequências respiratórias em relação às rações ricas em concentrados, isto em virtude da elevação do metabolismo, para realizar a digestão; quando o animal consome alimento muito fibroso ele gera um incremento calórico maior, em função das atividades realizadas a nível de rúmem, o que o leva a diminuir a ingestão de alimentos resultando em menor quantidade de calor a ser dissipada, beneficiando o balanço energético entre o animal e o ambiente.

Observa-se, também, que os animais da raça Sindi tiveram CPB e CFDN $\left(\mathrm{kg} \mathrm{d}^{-1}\right)$ semelhantes e o consumo de CFDA ( $\mathrm{kg} \mathrm{d}^{-}$ $\left.{ }^{1}\right), \operatorname{CMM}\left(\mathrm{kg} \mathrm{d}^{-1}\right)$ e o CEE $\left(\mathrm{kg} \mathrm{d}^{-1}\right)$ diferiu estatisticamente $(\mathrm{p}<$ 0,05 ) entre si, com maior consumo por parte dos animais da raça Guzerá. Esses maiores consumos pelos animais da raça Guzerá podem ser atribuídos à sua menor ingestão de FDN, haja vista que a ingestão voluntária de matéria seca é relacionada ao conteúdo de FDN do alimento e da dieta, cuja fermentação e passagem de FDN pelo retículo-rúmen, são mais lentas que outros constituintes dietéticos, exercendo grande efeito no enchimento e sobre o tempo de permanência, comparado aos componentes não fibrosos do alimento (Barbosa et al., 2006). Como se pode observar na Tabela 6, a raça Guzerá obteve valores menores em CFDN (\%PV) aumentando, assim, os demais consumos. Para Olsson et al. (2004) o estresse térmico pode reduzir a ingestão de alimento, devido à taxa metabólica reduzida que resulta em sinais de feedback, indicando exigências menores de saída de energia, fato que não ocorreu no presente experimento, em que os animais estiveram em estresse térmico nos horários mais quentes do dia e mantiveram um consumo acima do estabelecido.

\section{CONCLUSÕES}

1. Os animais da raça Sindi e Guzerá demonstraram que estão bem adaptados às condições de Nordeste brasileiro, tendo em vista que não houve alterações em seus parâmetros fisiológicos, como a temperatura retal, superficial e a frequência respiratória sendo considerados, portanto, dentro da faixa normal para a espécie bovina.

2. Os animais apresentaram excelente desempenho produtivo e de consumo de nutrientes, durante todo o período experimental.

3. Novas pesquisas devem ser realizadas para que sejam definidas as faixas bioclimáticas ideais para os animais zebuínos criados no Nordeste brasileiro.

\section{LITERATURA CITADA}

Azevedo, D. M. M. R.; Alves, A. A.; Feitosa, F. S.; Magalhães, J. A.; Machado, C. H. M. Adaptabilidade de bovinos da raça Pé-Duro às condições climáticas do semiárido do estado do Piauí. Archivos de Zootecnia, v.57, p.513-523, 2008.

Baêta, F. C.; Souza, C. F. Ambiência em edificações rurais Conforto animal. 2.ed. Viçosa: UFV, 2010, 269p.

Barbosa, N. G. S.; Lana, R. P.; Ham, N. J. Consumo e fermentação rumina de fibras em função de suplementação alimentar energética e protéica em novilhos. Revista Brasileira de Zootecnia, v.30, p.1558-1565, 2006.

Bianchini, E.; McManus, C.; Lucci, C. M.; Fernandes, M. C. B.; Prescott, E.; Mariante, A. da S.; Egito, A. A. Características corporais associadas com a adaptação ao calor em bovinos naturalizados brasileiros. Pesquisa Agropecuária Técnica, v.41, p.1443-1448, 2006.

Costa, M. A. L; Valadares Filho, S. C.; Valadares, R. F. D. Validação das equações do NRC (2001) para predição do valor energético de alimentos em condições brasileiras. Revista Brasileira de Zootecnia, v.34, p.280-287, 2005.

Detmann, E.; Valadares Filho, S. C.; Pina, D. S.; Henriques, L. T.; Paulino, M. F.; Magalhães, K. A.; Silva, P. A.; Chizzotti, M. L. Prediction of the energy value of cattle diets based on the chemical composition of the feeds under tropical conditions. Animal Feed Science and Technology, v.143, p.127-147, 2008.

Façanha, D. A. E.; Silva, R. G. da; Maia, A. S. C.; Guilhermino, M. M.; Vasconcelos, A. M. de. Variação anual de características morfológicas e da temperatura de superfície do pelame de vacas da raça Holandesa em ambiente semiárido. Revista Brasileira de Zootecnia, v.38, p.837-844, 2010.

Ferreira, F.; Pires, M. F. A.; Martinez, M. L.; Coelho, S. G.; Carvalho, A. U.; Ferreira, P. M.; Facury Filho, E. J.; Campos, W. E. Parâmetros fisiológicos de bovinos cruzados submetidos ao estresse calórico. Arquivo Brasileiro de Medicina Veterinária e Zootecnia, v.58, p.732-738, 2006. 
Ferreira, R. A. Maior produção com melhor ambiente para aves, suínos e bovinos. Viçosa: Aprenda Fácil Editora, 2005. 371p.

Furtado, D. A.; Peixoto, A. P.; Nascimento, J. W. B. do; Regis, J. E. F. Environmental comfort in constructions for Sindi and Guzera calves in the agreste region of the state of Paraiba. Engenharia Agrícola, v.32, p.1-9, 2012.

Hahn, G. L.; Parkhurrst, A. M.; Gaughan, J. B. Cattle respiration rate as a function of ambient temperature. Transactions of American Society of Agricultural Engineering, v.40, p.97121, 1997.

Jorge, A. M.; Fontes, C. A. A.; Paulino, M. F.; Gomes Júnior, P.; Ferreira, J. N. Desempenho produtivo de animais de quatro raças zebuínas, abatidos em três estádios de maturidade. 1. Ganho de peso e de carcaça e eficiência de ganho. Revista Brasileira de Zootecnia, v.27, p.766-769, 2007.

Martello, L. S.; Sasvastano Júnior, H.; Silva, S. L. da; Titto, E. A. L. Respostas fisiológicas e produtivas de vacas holandesas em lactação submetidas a diferentes ambientes. Revista Brasileira de Zootecnia, v.33, p.181-191, 2004.

NRC - National Research Council - Nutrient requirements of beef cattle. 7.ed. Washington: National Academy Press, 1996. $242 \mathrm{p}$.

Oliveira, P. T. L.; Turco, S. H. N.; Araújo, G. G. L.; Voltolini, T. V.; Menezes, D. R.; Silva, T. F. Comportamento ingestivo e parâmetros fisiologicoa de bovinos Sindi alimentados com teores crescentes de feno de erva-sal. Revista Brasileira de Ciências Agrárias, v.7, p.180-188, 2012.

Olsson, K.; Hermelin-Josater, M.; Hilali-Hossaine, J.; Hydbring, E.; Dahlborn, K. Heat stress causes excessive drinking in fed and food deprived pregnant goats. Comparative Biochemistry and Physiology, v.10, p.309-326, 2004.
Pacheco, P. S.; Restle, J.; Silva, J. H. S. Desempenho de novilhos jovens e superjovens de diferentes grupos genéticos terminados em confinamento. Revista Brasileira de Zootecnia, v.34, p.963-975, 2005.

Pereira, J. C. C. Fundamentos de bioclimatologia aplicados à produção animal. 1. Ed. Belo Horizonte: FEPMUZ Editora, 2005. 195p.

Silva, D. J.; Queiroz, A. C. Análise de alimentos: Métodos químicos e biológicos. Viçosa: UFV, 2002. 235p.

Silva, F. de A. S. e.; Azevedo, C. A. V. de. A new version of the Assistat Statistical Assistance Software. In: World Congress on computers in agriculture, 4, Orlando-FL-USA: Anais... Orlando: American Society of Agricultural Engineers, 2006. p.393-396.

Souza, B. B.; Silva, R. M. N. da; Marinho, M. L.; Silva, G. A.; Silva, E. M. N.; Souza, A. P. Parâmetros fisiológicos e índice de tolerância ao calor de bovinos da raça Sindi no semiárido paraibano. Ciência e Agrotecnologia, v.31, p.883-888, 2007.

Souza, C. F; Tinôco, I. de F. F; Baêta, F. C.; Ferreira, W. P. M.; Silva, R. S. Avaliação de materiais alternativos para confecção do termômetro de globo. Ciência e Agrotecnologia, v.26, p.157-164, 2002.

Turco, S. H. N.; Araújo, G. G. L.; Teixeira, A. H. C. Temperatura retal e freqüência respiratória de bovinos da raça Sindi do semiárido brasileiro. In: Reunião Anual da Sociedade Brasileira de Zootecnia, 34, 1990, Porto Alegre. Anais... Porto Alegre: SBZ, 1990. CD Rom

Turco, S. H. N.; Silva, T. G. F.da; Santos, L. F. C. dos; Ribeiro, P. H. B.; Araújo, G. G. L de; Holanda Júnior, E. V.; Aguiar, M. A. Zoneamento bioclimatico para vacas leiteiras no estado da Bahia. Engenharia Agrícola, v.26, p.20-27, 2006. 